Research Article

\title{
Prescribing pattern of antibiotics in pedodontics OPD of tertiary care dental hospital in Dhule district
}

\author{
Swapnil Balkrishna Kaikade*, Nitin Dnyaneshwar Pise
}

\author{
Department of Pharmacology, \\ Maharashta, India \\ Received: 16 May 2016 \\ Accepted: 09 June 2016 \\ *Correspondence to: \\ Dr. Swapnil Balkrishna \\ Kaikade, \\ Email: skaikade@ \\ rediffmail.com
} ACPM Medical College, Dhule,

Copyright: (C) the author(s), publisher and licensee Medip Academy. This is an openaccess article distributed under the terms of the Creative Commons Attribution NonCommercial License, which permits unrestricted noncommercial use, distribution, and reproduction in any medium, provided the original work is properly cited.

\begin{abstract}
Background: Antibiotics are prescribed in dental practice for prophylactic and therapeutic reasons. Prophylactic antibiotics are prescribed to prevent diseases caused by members of the oral flora introduced to distant sites in a host at risk or introduced to a local compromised site in a host at risk. Although a number of studies on antibiotic use have been carried out, controversies still exist in areas such as prophylaxis, interactions and their use after both minor and intermediate oral surgical procedures. These controversies lead to inappropriate and unnecessary antibiotic use in humans. The objective of this study was to study prescribing frequency of antimicrobial agents and to study prescribing frequency of particular brand of antibiotic agent.

Methods: A descriptive study was conducted in outpatient department of pedodontics of a tertiary care teaching hospital. Three hundred prescriptions were randomly collected over a period of 30 days. The data was then analysed to find out the prescribing pattern.

Results: In the present study, $67 \%$ of the total prescriptions had at least one antibiotic and amoxicillin is the most frequently prescribed antibiotic while coamoxyclav is the most frequently prescribed fixed dose combination. Amongst fixed dose combination of amoxycillin and clavulanic acid, megamox CV $(55 \%)$ is the most frequently prescribed brand followed by moxclav kid (34\%). For amoxycillin, novamox $(60 \%)$ is the most frequently prescribed brand followed by moxkid (31\%) and megamox (8\%).

Conclusions: Most reports on antibiotic use in dentistry show amoxicillin or other penicillin-based drugs to be the most commonly used. This trend is based on the established efficacy of penicillin based drugs on bacteria involved in odontogenic infections. Increasingly resistant strains are being reported in odontogenic infections, hence the need for constant antibiotic pharmacovigilance.
\end{abstract}

Keywords: Prescription pattern, Antibiotics, Pedodontics, OPD

\section{INTRODUCTION}

Antimicrobial drugs are the greatest contribution of the 20 th century to therapeutics. They are one of the few drugs which can cure rather than just palliate disease. As a class, they are one of the most frequently used as well as misused drugs. ${ }^{1}$ Management of oral infections presents a big portion of the work handled by oral health care providers. 2,3

Apart from analgesics, they are the commonest drugs that dentists routinely prescribe themselves.
Antibiotics are prescribed in dental practice for prophylactic and therapeutic reasons. Prophylactic antibiotics are prescribed to prevent diseases caused by members of the oral flora introduced to distant sites in a host at risk or introduced to a local compromised site in a host at risk. ${ }^{4}$ Therapeutic antibiotics are prescribed in most cases to treat diseases of the hard and soft tissues in the oral cavity. ${ }^{5}$

Although a number of studies on antibiotic use have been carried out, controversies still exist in areas such as prophylaxis, interactions and their use after both minor and intermediate oral surgical procedures. These 
controversies lead to inappropriate and unnecessary antibiotic use in humans.

This misuse contributes to development of specific antibiotic resistant strains. ${ }^{6}$ Bacteria in most oral infections are indigenous to the oral cavity and the effective antibiotics against them are known. However, reports of emerging resistant strains to these drugs are worrisome. ${ }^{7,8}$ One of the major cause of this emerging resistance is inappropriate and unnecessary use of antibiotics, this leads to dominance of resistance among microorganisms. ${ }^{8}$

Unnecessary uses of antibiotics are reported in children. ${ }^{9}$ mostly for ear and dental infections. However, in children, increasing microbial resistance to antibiotics is a well-documented and is a serious global health concern. $^{10,11}$

One way of preventing development of antibiotic resistant strains is by the rational use of these drugs. However, this can only be possible if the health care providers are aware and adhere to available antibiotic prescription guidelines. ${ }^{12,13}$ Additionally, they should be updated of emerging resistant strains. Despite the existence of guidelines, there are differences in level of knowledge and approach to antibiotic prescription among professional health care providers. ${ }^{14}$

The aim of the present study was to determine the pattern of antibiotic prescription in OPD of tertiary care dental teaching hospital.

The objective of this study was to study the prescription pattern of antibiotics in pedodontic OPD. And study prescribing frequency of antimicrobial agents, to study prescribing frequency of particular brand of antibiotic agent.

\section{METHODS}

A descriptive study was conducted in outpatient department of pedodontics of a tertiary care teaching hospital. Three hundred prescriptions were randomly collected over a period of 30 days.

The data was then analysed to find out the prescribing pattern.

\section{RESULTS}

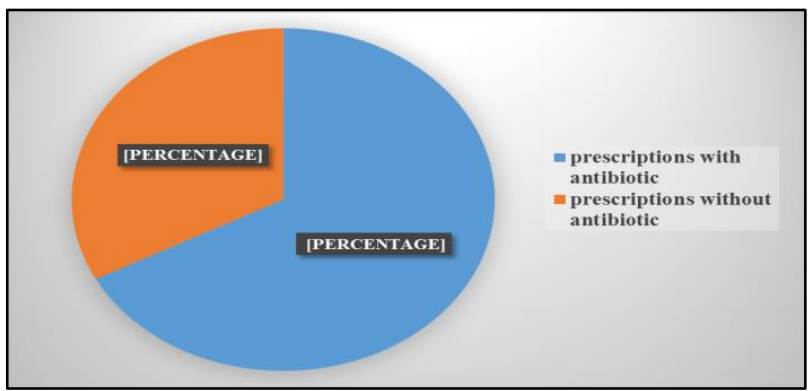

Figure 1: Prescribing frequency of antibiotics.
It was found that $67 \%$ of the total prescriptions had one or more antibiotic in it and rest $33 \%$ had no antibiotic.

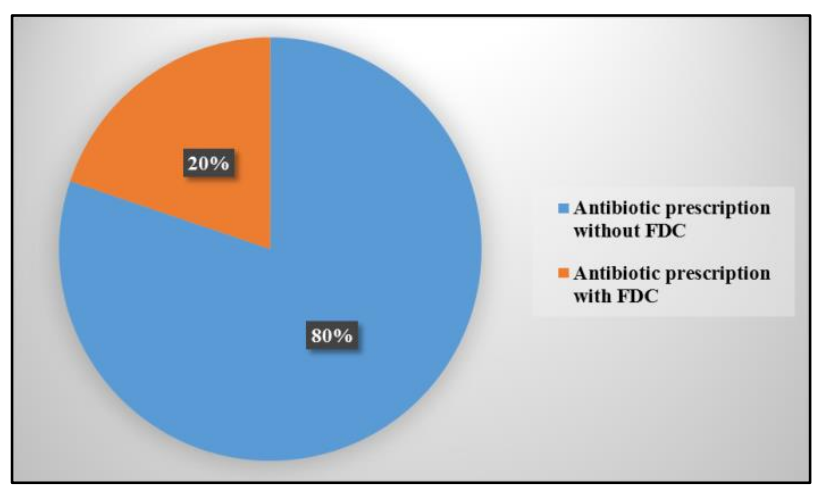

Figure 2: Prescribing frequency of FDC.

It is seen that $20 \%$ of the total prescriptions with antibiotics had one or more fixed dose combination while $80 \%$ of the prescriptions had no fixed dose combinations.

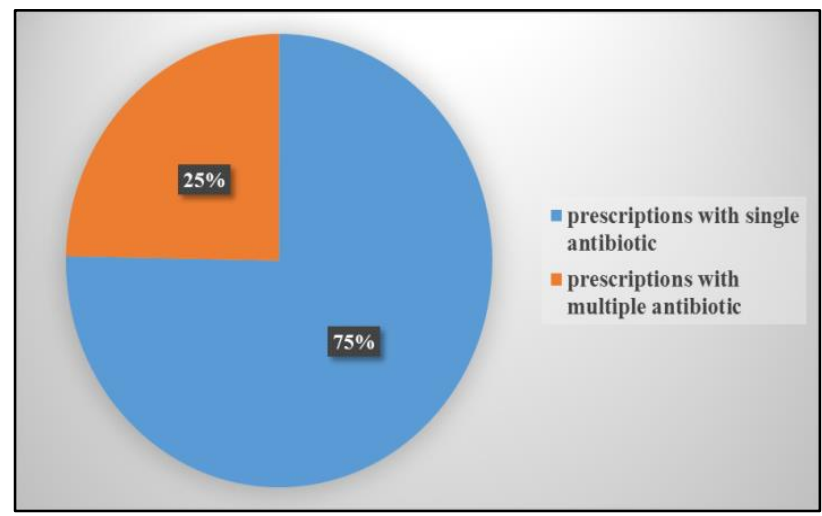

Figure 3: Prescribing frequency of single and multiple antibiotics.

This chart shows that out of all the antibiotic prescriptions without fixed dose combination, $75 \%$ of the prescriptions had more than one antibiotic and $25 \%$ prescriptions had only one antibiotic in it.

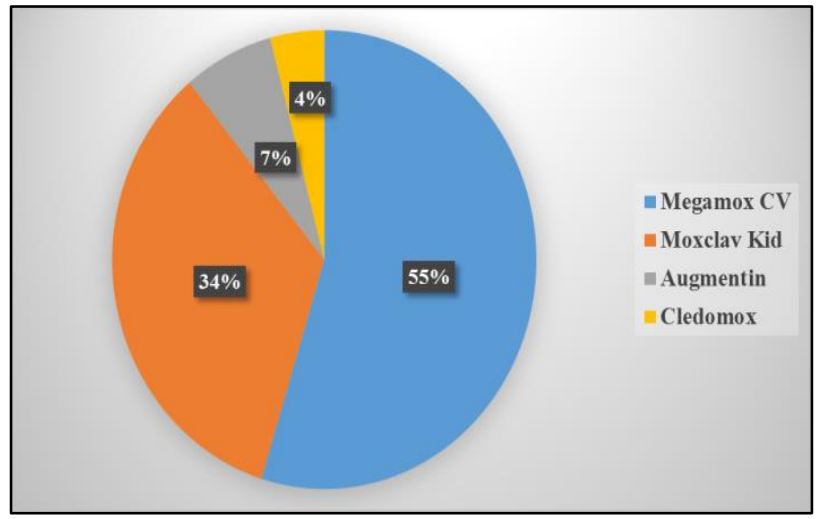

Figure 4: Prescribing frequency of amoxycillin and clavulanic acid FDC (Brand). 
This chart shows that megamox $\mathrm{CV}$ is the most frequently prescribed fixed dose combination of amoxicillin and clavulanic acid followed by moxclav kid (34\%), augmentin $7 \%$ and cledomox $4 \%$.

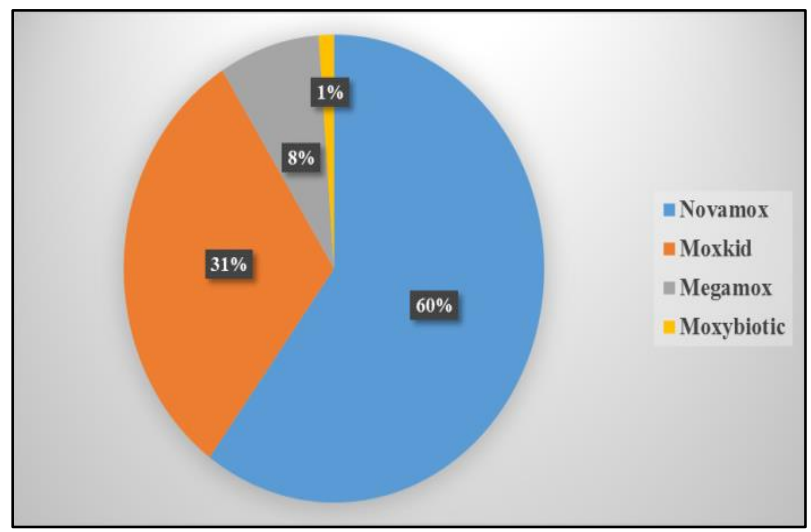

Figure 5: Frequency of prescribing various amoxycillin brands.

This chart shows that novamox $(60 \%)$ is the most frequently prescribed amoxicillin brand followed by moxkid $(31 \%)$.

\section{DISCUSSION}

Many factors have been reported to influence antibiotic prescription pattern among dental health care practitioners. These range from patient preferences, treatment methods, prevalence of disease, available resources and the existence and application of clinical guidelines. $^{15,16}$

In the present study, $67 \%$ of the total prescriptions had at least one antibiotic and amoxicillin is the most frequently prescribed antibiotic while co-amoxyclav is the most frequently prescribed fixed dose combination which accounts for $20 \%$ of the total prescriptions with FDCs in it.

While most of the prescriptions (75\%) had only one antibiotic, $25 \%$ prescriptions had two or more than two antibiotics in it but no FDC.

Amongst fixed dose combination of amoxycillin and clavulanic acid, megamox $\mathrm{CV}(55 \%)$ is the most frequently prescribed brand followed by moxclav kid $(34 \%)$.

For amoxycillin, novamox $(60 \%)$ is the most frequently prescribed brand followed by moxkid (31\%) and megamox $(8 \%)$.

Most reports on antibiotic use in dentistry show amoxicillin or other penicillin-based drugs to be the most commonly used. This trend is based on the established efficacy of penicillin based drugs on bacteria involved in odontogenic infections. Increasingly resistant strains are being reported in odontogenic infections, hence the need for constant antibiotic pharmacovigilance.

Funding: No funding sources

Conflict of interest: None declared

Ethical approval: The study was approved by the Institutional Ethics Committee

\section{REFERENCES}

1. Tripathi KD. Antimicrobial drugs: general considerations; essentials of medical pharmacology; $7^{\text {th }} \mathrm{Ed}$

2. Montazem A. Antibiotic prophylaxis in dentistry. Mt Sinai J Med. 1998;65;388-92.

3. Poeschl PW, Eckel D, Poeschl E. Postoperative prophylactic antibiotic treatment in third molar surgery- a necessity? J Oral Maxillofac Surg. 2004;62:3-8.

4. Dajani AS, Taubert KA, Wilson W, Bolger AF, Bayer A, Ferrieri P, et al. Prevention of bacterial endocarditis: recommendations of american heart association. J Am Dent Assoc. 1997;277:1794-801.

5. Fine DH, Hammond BF, Loesche WJ. Clinical use of antibiotics in dental practice. Int $\mathbf{J}$ Antimicrob Agents. 1998;9:235-8.

6. Van De, Grundmann H, Verloo D, Tiemersma E, Monen J, Goossens H, et al. Antimicrobial drug use and resistance in Europe. Emerg Infect Dis. 2008; $14: 1722-30$.

7. Peterson LJ. Antibiotics: their use in therapy and prophylaxis. In: Topazian RG, Goldenberg MH, eds. Management of infections of the oral and maxillofacial region. $2^{\text {nd }}$ ed. Philadelphia: WB Saunders Company; 1987.

8. American dental council on antibiotic use in dentistry. J Am Dent Assoc. 1997;128:64-8.

9. Tenover FC, Hughes JM. The challenges of emerging infectious diseases: development and spread of multiply-resistant bacterial pathogens. J Am Med Assoc. 1996;275:300-4.

10. Smith A, Bagg J. An update on antimicrobial chemotherapy, 3: antimicrobial resistance and the oral cavity. Dent Update. 1998;25:230-4.

11. American dental association council on scientific affairs. Antibiotic use in dentistry. J Am Dent Assoc. 1997; $128: 648$.

12. Ashrafian H, Bogle RG. Antimicrobial prophylaxis for endocarditis: emotion or science? Heart. 2007;93:5-6.

13. Council on clinical affairs. Guidelines on appropriate use of antibiotic therapy for pediatric dental patients. In: American academy of pediatric entistry reference manual. American Academy of Pediatric Dentistry. 2010;29:246-8. Available at http://www.aapd.org/media/policies_guidelines/g_ant ibiotictherapy.pdf.

14. Yehuda Z, Liran L. Clinical decision making in restorative dentistry, endodontics, and antibiotic prescription. J Dent Educ. 2008;72:81-6. 
15. Salako NO, Rotimi VO, Adib SM, Al-Mttawa S. Pattern of antibiotic prescription in the management of oral diseases among dentists in Kuwait. J Dent. 2004;32:503-9.
16. Demirbas F, Gjermo P, Preus HR. Antibiotic prescribing practices among Norwegian dentists. Acta Odontal Scand. 2006;64;355-9.

Cite this article as: Kaikade SB, Pise ND.

Prescribing pattern of antibiotics in pedodontics

OPD of tertiary care dental hospital in Dhule district. Int J Basic Clin Pharmacol 2016;5:1462-5. 